\title{
Interfaces entre os campos da comunicação
}

e da informação ${ }^{1}$

Relationships between communication and Information science

SÔNIA DOMINGUES SANTOS BRAMBILLA Doutoranda do PPGCOM/UFRGS.sdbrambilla@yahoo.com.br

RITA DO CARMO FERREIRA LAIPELT Mestre em Comunicação e Informação pelo PPGCOM/UFRGS.ritacarmo@yahoo.com.br

SÔNIA ELISA CAREGNATO

Professora Adjunta do Depto. de Ciências da Informação e PPGCOM/UFRGS; Coordenadora do Grupo de Estudos em Comunicação Científica; Pesquisadora CNPq. caregnat@ufrgs.br

IDA REGINA C. STUMPF

Professora Titular do Depto. de Ciências da Informação e do PPGCOM/UFRGS; Coordenadora do Grupo de Estudos em Comunicação Científica/UFRGS; Pesquisadora CNPq.irstumpf@ufrgs.br

\begin{abstract}
Resumo
Este trabalho é fruto dos estudos das relações entre Comunicação e Ciência da Informação desenvolvidos no âmbito do Grupo de Pesquisa em Comunicaçāo Científica do PPGCOM/UFRGS. Testou-se uma metodologia para identificar interfaces entre a Comunicação e a Ciência da Informação pela análise da ementa das linhas de pesquisa dos Programas de Pós-Graduação das duas áreas no Brasil. Os resultados mostraram que, entre as interfaces encontradas, tecnologias, organização, representaçāo e gestão da informação são convergências dos dois campos, com abordagens distintas. As ciências estão ampliando fronteiras interdisciplinares: a Ciência da Informação volta-se para as questōes sociais, e a Comunicação, para o uso dos recursos e técnicas informacionais, delineando questōes e traçando rumos para o surgimento de novos paradigmas.
\end{abstract}

Palavras-chave: ciência da informação, comunicação, pós-graduação - estudos, interfaces.

\section{Introdução e justificativa}

A Ciência da Informação e a Ciência da Comunicação são freqüentemente caracterizadas como disciplinas cujos campos se encontram "em construção". Ambas têm perspectivas interdisciplinares e fronteiras porosas e estão associadas com as tecnologias e práticas sociais, principalmente no que toca ao fenômeno da explosão informacional. Há entre elas uma área de conexão, tanto para delimitar fronteiras quanto para expor convergências. São campos que se estruturaram por meio de um corpus teórico próprio, mas, para afirmarem-se como legítimos, precisam também travar relaçōes com outros campos e desenvolver vínculos.
Pode-se fazer uma generalização, afirmando que tudo é comunicação ou que tudo é informação, o que provoca dispersão nos estudos e indefinição das fronteiras devido a essa "vocação interdisciplinar" (BRAGA, 2004). No entanto, não se pode, sob a justificativa da interdisciplinaridade, apenas unir temas e/ou autores de forma arbitrária ou por necessidades conjunturais. É preciso identificar diversidades e interações entre as áreas para que uma não se interponha à outra. Segundo Oliveira (1998, p. 144), “[...] as carências técnicas [...] podem ser parcialmente resolvidas pela interdisciplinaridade", entretanto, é preciso um domínio da área de pesquisa para poder julgar a conveniência do "empréstimo teórico" e a
1 Versão preliminar apresentada no VII ENANCIB - Encontro Nacional de Pesquisa em Ciência da Informação, Marília, SP, 2006. 
articulação entre os campos, entre o que não é específico de um, mas comum aos dois.

Este trabalho é fruto dos estudos das relações entre Comunicação e Ciência da Informação desenvolvidos no âmbito do Grupo de Pesquisa em Comunicação Científica do Programa de Pós-Graduação em Comunicação e Informação (PPGCOM) da Universidade Federal do Rio Grande do Sul (UFRGS). Testou-se uma metodologia para verificar a ocorrência de interfaces entre as áreas do conhecimento. Para tanto, buscou-se identificar interfaces entre a Comunicação e a Ciência da Informação por meio da análise da ementa das linhas de pesquisa dos Programas de Pós-Graduação das duas áreas no Brasil. O objetivo foi identificar um espaço pertencente aos dois campos e por eles compartilhado. Especificamente, analisou-se como ocorre a justaposição nas ementas das linhas de pesquisa e se as linhas dos programas dos dois campos apresentam convergências. $\mathrm{O}$ estudo tem natureza exploratória e abordagem qualitativa, utilizando como método a análise de conteúdo. Os objetos do estudo foram:

- 58 ementas das linhas de pesquisa dos 19 programas de pós-graduação em Comunicação avaliados pela CAPES em 2004;

- 19 ementas das linhas dos sete programas de pós-graduação em Ciência da Informação avaliados pela CAPES em 2004.

Optou-se pela análise de conteúdo como metodologia por esta permitir a interpretação dos significados de forma abrangente e por auxiliar "[...] a reinterpretar as mensagens e a atingir uma compreensão de seus significados, que vai além de uma leitura comum" (MORAES, 1999, p. 9). Foram formadas três categorias, atendendo aos seguintes critérios: a) categoria "Informação E Comunicação": obtida pela análise das ementas das linhas de pesquisa dos Programas de Ciência da Informação, para localizar o termo comunicação e derivativos;

b) categoria "Comunicação E Informação": obtida pela análise das ementas das linhas de pesquisa dos Programas de Comunicação, para localizar o termo informação e derivativos;

c) categoria "interdisciplinaridade": obtida pela análise das ementas das linhas de pesquisa dos Programas de Comunicação e de Ciência da Informação, para localizar o termo interdisciplinaridade e derivativos, na busca de evidências de relações entre as áreas;

A categorização permitiu observar o fenômeno da interface entre a Comunicação $E$ a Ciência da Informação. $\mathrm{O} E$, aqui grifado, é um espaço de intersecção, e não uma conjunção gramatical ou operador de soma aritmética. De acordo com a lógica booleana, o $E$ (and), nas operaçôes com conjuntos de elementos, exclui dos universos a parte específica, mas mantém o que é comum, como pode ser visualizado na Figura 1 (abaixo).

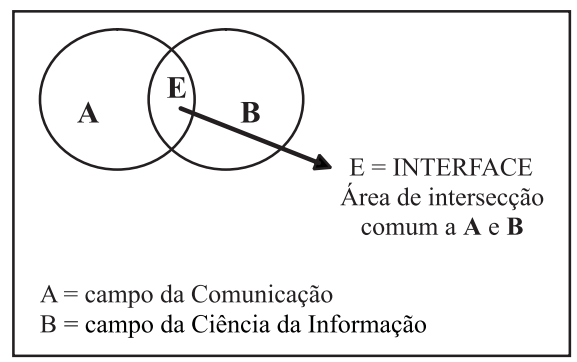

Figura 1: Interfaces entre o Campo da Comunicação e da Ciência da Informação.

Para Devèze (2000), essa área comum seria um ponto de reunião que forma campos de interações, de interferências, criando espaços novos com potencialidades positivas e negativas. 
Já na concepção de Braga (2004), as práticas da pesquisa dão o direcionamento da construção de uma área. Segundo o autor, o termo "interface" parece ser mais adequado do que "interdisciplinaridade" para referir-se a atividades, no espaço social, pertencentes a áreas diferenciadas que comparecem com seu acervo de práticas e de conhecimentos, confluindo na mesma direção. Assim, interface seria "[...] área de tensão e não simplesmente espaço de sobreposição de objetivos e compartilhamentos harmônicos ou panorâmicos de investigação" (p. 17). Trata-se de zonas problemáticas por definição, que devem ser investigadas na busca de: conhecer a situação social permeada por um e outro campo; perceber a contribuição para outros ângulos de interesse, problemas e desafios gerados pelas articulações; e ter visão abrangente para construir o específico de cada um (BRAGA, 2004).

\section{Pós-graduação em comunicação e ciência da informação}

Os programas de pós-graduação (PPGs) em Comunicação e Ciência da Informação estão localizados, de acordo com a classificação do Conselho Nacional de Desenvolvimento Científico e Tecnológico (CNPq), em Ciências Sociais Aplicadas. Estruturam-se por áreas de concentração, que são "[...] indicações que condensam ou retratam as intenções dos cursos" (FAUSTO NETO, 1996, p. 86), e linhas de pesquisa, que representam temas aglutinadores de estudos científicos investigativos, de onde se originam projetos com afinidades entre si. (COORDENAÇÃO..., 2006). O primeiro PPG em Comunicação do Brasil foi o da Universidade de São Paulo (USP), criado em 1972, e o primeiro Doutorado é de 1980. Em 2006, data da coleta de dados deste estudo, havia 27 programas reconhecidos pela CAPES, como mostra o Quadro 1 (página seguinte).

O Quadro 1 evidencia que, dos 27 programas, apenas 12 oferecem Doutorado e Mestrado e que 19 estão nomeados genericamente como Comunicação, Ciências da Comunicação ou Comunicação Social. Nos demais, os nomes sugerem inter-relacionamentos com outras disciplinas ou tratam de temas específicos da área. Neste trabalho, são analisadas as linhas de pesquisa dos 19 programas que constaram da avaliação anual da CAPES em 2004, excetuados os grifados em negrito no Quadro 1 (página seguinte).

Quanto à pós-graduação em Ciência da Informação, o primeiro programa data de 1970, sendo de 1992 o primeiro doutorado específico na Universidade de Brasília (UnB). A estrutura atual (2006) é de oito programas, sendo que sete fazem parte deste estudo por terem sido avaliados pela CAPES em 2004, conforme se apresenta no Quadro 2 (página seguinte).

Percebe-se, na comparação com o número de programas da Comunicação, que a Ciência da Informação no Brasil é ainda uma área menos desenvolvida. São oito programas, sendo que apenas cinco com Doutorado e Mestrado. $\mathrm{Na}$ análise do nome dos programas, pode-se inferir a tendência atual do termo "Ciência(s) da Informação", abarcando várias áreas que têm como objeto de estudo a Informação, como a Biblioteconomia e a Arquivologia, por exemplo. Destaca-se a Universidade de São Paulo (USP), que incluía, até 2005, "Ciência da Informação e Documentação" como área de concentração do PPG em Comunicação. Esse quadro foi modificado pela implantação de um programa específico em Ciência da Informação e ainda faz parte, neste estudo, do campo da Comunicação. 
Quadro 1: Programas de Pós-Graduação em Comunicação no Brasil, reconhecidos pela CAPES até 2006.

\begin{tabular}{|c|c|c|c|c|c|}
\hline \multirow{2}{*}{\multicolumn{2}{|c|}{ Programas de Pós-graduação em Comunicação }} & \multirow{3}{*}{$\begin{array}{l}\text { IES } \\
\text { FAM }\end{array}$} & \multirow{3}{*}{$\begin{array}{l}\text { UF } \\
S P\end{array}$} & \multicolumn{2}{|c|}{ Conceito } \\
\hline & & & & \multirow{2}{*}{$\frac{M}{3}$} & \multirow{2}{*}{ D } \\
\hline 1 & Comunicação* & & & & \\
\hline 2 & Ciências da comunicação & UNISINOS & RS & 5 & 5 \\
\hline 3 & Ciências da comunicação & USP & SP & 3 & 3 \\
\hline 4 & Comunicação & UNB & DF & 4 & 4 \\
\hline 5 & Comunicação* & UFG & GO & 3 & - \\
\hline 6 & Comunicação & UFJF & $M G$ & 3 & - \\
\hline 7 & Comunicação & UFPE & $P E$ & 4 & - \\
\hline 8 & Comunicação & UFRJ & $R J$ & 4 & 4 \\
\hline 9 & Comunicação & UFF & $\mathrm{RJ}$ & 5 & 5 \\
\hline 10 & Comunicação & UERJ & $R J$ & 3 & - \\
\hline 11 & Comunicação & PUC-RIO & $R J$ & 3 & - \\
\hline 12 & Comunicação* & UFSM & RS & 3 & - \\
\hline 13 & Comunicação & UNESP/BAU & SP & 3 & - \\
\hline 14 & Comunicação* & FCSCL & $S P$ & 3 & - \\
\hline 15 & Comunicação & UNIMAR & SP & 3 & - \\
\hline 16 & Comunicação & UNIP & SP & 3 & - \\
\hline 17 & Comunicação e cultura* & UNISO & SP & 3 & - \\
\hline 18 & Comunicação e cultura contemporânea & UFBA & $\mathrm{BA}$ & 5 & 5 \\
\hline 19 & Comunicação e informação & UFRGS & RS & 4 & 4 \\
\hline 20 & Comunicação e linguagens & UTP & PR & 3 & - \\
\hline 21 & Comunicação e práticas de consumo* & ESPM & SP & 3 & - \\
\hline 22 & Comunicação e semiótica & PUC/SP & SP & 4 & 4 \\
\hline 23 & Comunicação social & UFMG & $M G$ & 5 & 5 \\
\hline 24 & Comunicação social & PUC/RS & RS & 5 & 5 \\
\hline 25 & Comunicação social & UMESP & SP & 4 & 4 \\
\hline 26 & Comunicação social: interações midiáticas* & PUC/MG & $M G$ & 3 & - \\
\hline 27 & Multimeios & UNICAMP & SP & 4 & 4 \\
\hline
\end{tabular}

Fonte: Documentos CAPES. Disponivel em: < http://www1.capes.gov.br> Acesso em: 05 jul. 2006.

Notas: M - Mestrado, D - Doutorado.

* 0 grifo em negrito refere-se aos Programas não analisados neste estudo.

Quadro 2: Programas de Pós-Graduação em Ciência da Informação no Brasil, reconhecidos pela CAPES até 2006.

\begin{tabular}{|c|l|c|c|c|c|}
\hline \multicolumn{2}{|c|}{ Programas de pós-graduação em ciência da informação } & \multirow{2}{*}{ IES } & \multirow{2}{*}{ UF } & \multicolumn{2}{|c|}{ Conceito } \\
\cline { 5 - 6 } & & UFBA & BA & 3 & D \\
\hline 1 & Ciência da informação & UFSC & SC & 3 & - \\
\hline 2 & Ciência da informação & USP & SP & 4 & 4 \\
\hline 3 & Ciência da informação * & UNESP/MAR & SP & 4 & 4 \\
\hline 4 & Ciência da informação & PUCCAMP & SP & 3 & - \\
\hline 5 & Ciência da informação & UNB & DF & 5 & 5 \\
\hline 6 & Ciências da informação & UFMG & MG & 5 & 5 \\
\hline 7 & Ciências da informação & UFF/IBICT & RJ & 4 & 4 \\
\hline 8 & Ciênncias da informaçãa & J & & \\
\hline
\end{tabular}

Fonte: Documentos CAPES. Disponível em: < http://www1.capes.gov.br> Acesso em: 05 jul. 2006.

Notas: M - Mestrado, D - Doutorado.

* 0 grifo em negrito refere-se ao Programa não analisado neste estudo. 
Também cabe citar o PPG em Comunicação e Informação da Universidade Federal do Rio Grande do Sul (UFRGS), que investiga os dois campos teóricos, mas pertence, para efeitos de avaliação da CAPES, ao Comitê de Comunicação.

\section{Campo da comunicação e campo da ciência da informação}

Para que se possam investigar as interfaces entre Ciência da Informação e Comunicação, deve-se refletir sobre questōes essenciais a cada um dos campos. Conceituando o campo Comunicação, Martino (2001) apresenta a ciência como produto de um encontro social, da transmissão de idéias, informações e mensagens, tornando comum o mesmo objeto mental. Já para França (2001, p. 41) “[...] Comunicação é um processo social básico de produção e partilhamento de sentido através da materialização de formas simbólicas”. Dessas definiçôes depreende-se que a essência da Comunicação está na representação dos sentidos, compartilhados entre as pessoas através da linguagem. Conforme observado por Peruzzo (2002, p. 52) “[...] o campo multifacetado da Comunicação situa-se num patamar altamente complexo e movediço [...] seus paradigmas estão em processo constante de construção e consolidação teórica".

Já a interdisciplinaridade é definida por Braga (2004) como concorrência de várias disciplinas para a elaboração conceitual e/ou metodológica do tratamento de uma pesquisa. Para o autor, não basta adotar um objeto empírico, é preciso formular problematizações específicas que caracterizem o que há de comunicacional no campo. Quanto mais próximo da realidade social o objeto estiver, mais as ciências entrecruzam-se e permeiam-se.
Complementando, Issler (2002) diz que duas ou mais ciências podem ter o mesmo objeto sem que tenham os mesmos objetivos e conclui que a Comunicação pode, sim, ter objetos em comum com outras áreas, mas não se apossar de seus objetivos.

Com base na análise das linhas de pesquisa dos PPGs, Jacks (2003) enumera os grandes eixos temáticos da pesquisa em Comunicação no Brasil, sinalizando objetos de estudo, perspectivas teóricas ou relações interdisciplinares: Cultura, Informação, Jornalismo, Linguagem, Tecnologia, Política, Sociedade, Meios e Mídia, Educação, Teorias e Metodologias, Semiótica e Representações Sociais. Na relação da Comunicação consigo mesma, a autora destaca: Ficção Televisiva, Instituições e Organizações, Imagem e Som, Produtos e Produção, Gêneros e Formatos, Linguagem e Mensagem, Gestão e Planejamento, Segmentação e Multimeios.

No que concerne à Ciência da Informação, Carvalho (1999, p. 54) argumenta que o termo "informação" vem sendo utilizado com diferentes acepções "[...] para significar mensagens, notícias, novidades, dados, conhecimento, literatura, símbolos, signos e até mesmo dicas e sugestôes". Segundo Shannon e Weaver (1949), trata-se de uma redução de incertezas. Le Coadic (1996) caracteriza a informação como o produto do processo de comunicação, e Barreto (1994, p. 1) destaca que o fenômeno, entre seres humanos, é “[...] a adequação de um processo de comunicação que se efetiva entre o emissor e o receptor da mensagem". Assim, informação e comunicação fazem parte de um processo em que a primeira é o conteúdo da mensagem e a segunda é o meio pelo qual essa mensagem é divulgada. Ao unirem-se essas definições, pode-se inferir informação como representação das coisas do mundo (objetos, senti- 
mentos, mensagens, etc.), que podem reduzir incertezas e transformar estruturas cognitivas, levando a indagaçôes mais complexas e a novas incertezas, num ciclo contínuo...

Os estudos em Ciência da Informação surgiram, segundo Carvalho (1999), da demanda social pela otimização dos processos de coleta, armazenagem, recuperação e disseminação da informação científica e tecnológica, cuja produção apresentava um crescimento exponencial na década de 50. Loureiro (1999) destaca que o desenvolvimento da ciência aconteceu após a II Guerra Mundial, a partir da necessidade social de organizar a conseqüente explosão informacional e também de criar instrumentos para recuperação e disseminação da informação. Nesse sentido, evidenciamse os aspectos aplicados da ciência, orientados para sistemas, técnicas e equipamentos, porém ligados aos problemas sociais e culturais do mundo. Pinheiro (1999, p. 155) considera que a Ciência da Informação "[...] é uma ciência social, interdisciplinar por natureza, que apresenta interfaces com a Biblioteconomia, Ciência da Computação, Ciências Cognitivas, Sociologia da Ciência e Comunicação". Para Azevedo Netto (1999), ela tem atuação voltada aos processos informacionais no interior da comunicação. Conclui que é uma "[...] disciplina científica voltada para o estudo da informação em suas diferentes manifestações e fenômenos, no interior do social, por meio da interface com diferentes campos e domínios do saber [...]" (p. 138). Tais colocações possibilitam antever o objeto de estudo da ciência - a informação.

As tendências da pesquisa em informação podem apresentar diversos enfoques, como os estudos de usuários, de necessidade e uso e de acesso e busca à informação. Saracevic (1999) inclui na pesquisa básica em Ciência da Informação, a Matemática, a Lógica e a Estatística, o estudo dos aspectos sociais e técnicos do acesso, recuperação e disseminação da informação, além da Bibliometria, Webometria e Cientometria. Os pressupostos contemporâneos da Ciência da Informação estabelecem tais intersecçôes, influenciando a teoria e a prática para os seguintes paradigmas: físico, abrangendo pesquisas em tecnologia e recuperação da informação, aqui considerada um objeto material; cognitivo, em que o usuário é reconhecido como sujeito descontextualizado do coletivo; e social, em que a informação é caracterizada pelas ações da comunidade em que se insere (CAPURRO, 2003).

Após essa breve reflexão sobre Comunicação e Ciência da Informação, pode-se inferir que ambas apresentam interfaces com outros campos. Saracevic (1999) refere-se a isso, citando que, se existe alguma palavra que tenha mais conotações e usos em contextos discrepantes e que cause maior confusão que "informação", é "comunicação", sendo as duas significativamente relacionadas: "[...] informação é um fenômeno e comunicação é o processo de transferir ou compartilhar o fenômeno" (p. 6). No mesmo sentido, para Devèze (2000, p. 39) "[...] o que pode unir as várias facetas dos fenômenos de informação e de comunicação que constituem o objeto das Ciências da Informação e da Comunicação é a troca de mensagens de toda natureza entre os sujeitos humanos ou sociais". Saracevic (1995) constata abordagens similares, em diversos níveis, por ambas as ciências: colégios invisíveis, interação humana com tecnologias de comunicação, comportamento na busca de informação, teoria da informação e de sistemas e a sociedade da informação. Além destas, há os estudos relacionados à Semiótica, utilizada pela Ciência da Informação 
para criar linguagens de recuperação, sistemas de indexação e resumos ou para unificar a terminologia especializada (MERTA, 1969). Já a Comunicação utiliza Semiótica na codificação da informação e transmissão de mensagens. Santaella (2001, p. 46-47) estabelece inter-relações entre comunicação, semiótica e informação: "[...] a) não há comunicação sem transmissão de informação; b) não há informação que não seja encarnada numa mensagem; c) não há mensagem sem signos; d) não há transmissão de mensagens sem canal de transporte".

Mueller (1989) e Orozco Gómez (1996) reconhecem semelhanças entre os estudos de uso da Ciência da Informação e os estudos de recepção e de comunicação de massa, voltados ao uso e ao acesso à informação. A corrente de usos e gratificaçōes dos estudos de recepção investiga o que as pessoas fazem com os meios; a vertente latino-americana dá ênfase ao uso, para saber como os receptores se apropriam e usam o conteúdo das mensagens, enquanto que a vertente americana enfatiza a gratificação individual para diagnosticar necessidades comunicativas, psicológicas ou individuais na audiência.

Mas o destaque nas interfaces entre Comunicação e Informação são as tecnologias (TICs). Na Ciência da Informação, elas estão presentes, sobretudo, no desenvolvimento de estudos de recuperação de informação em bases de dados e nos impactos das tecnologias na sociedade. No campo da Comunicação, estão ligadas aos estudos de meios e também aos impactos sociais. Para Pinheiro (2004, p. 17), "Ciência da Informação, Comunicação e Ciência da Computação formam um triângulo disciplinar altamente dependente da nova ordem tecno-cultural [...] que poderá no futuro levar à formação de uma disciplina com características transdisci- plinares do tipo Infocomunicação". Um indício de que a Infocomunicação está se concretizando pode ser verificado na Comunicação Científica, através dos estudos relacionados às publicações científicas. Percebe-se que, com a popularização da publicação de periódicos eletrônicos online, cada vez mais os campos da Comunicação e da Ciência da Informação convergem, impulsionados principalmente pelo uso das TICs.

\section{Resultados}

$\mathrm{Na}$ categoria "Comunicação E Informação", entre as ementas das 58 linhas de pesquisa dos Programas de Pós-Graduação em Comunicação (PPGCOMs) investigadas, sete apresentaram o termo "informação" e seus derivativos (Quadro 3, página seguinte).

Para análise da categoria "Informação E Comunicação", das 19 ementas das linhas de pesquisa dos Programas de Pós-Graduação em Ciência da Informação (PPGCIs) investigadas, cinco apresentaram o termo "comunicação" e seus derivativos, como (Quadro 4, página seguinte).

$\mathrm{Na}$ categoria "Interdisciplinarida$d e$ ", formada pelas ementas das 77 linhas de pesquisa dos PPGCOMs e dos PPGCIs, foram encontradas quatro que apresentaram o termo "interdisciplinaridade" e derivativos (Quadro 5, página seguinte).

$\mathrm{Na}$ categoria "Comunicação E Informação" o termo "informação" é tratado nos PPGCOMs sob a ótica: da geração e uso da informação; das TICs; do fluxo, organização e gestão da informação. A linha de pesquisa "Informação, Tecnologias e Práticas Sociais" da UFRGS apresenta geração e uso da informação no contexto das práticas sociais, em que a interação das tecnologias leva ao surgimen- 
Quadro 3: Interfaces da comunicação e informação nas ementas das linhas de pesquisa dos PPGCOMs.

\begin{tabular}{|c|c|c|}
\hline $\begin{array}{l}\text { Programas de } \\
\text { pós-graduação }\end{array}$ & $\begin{array}{l}\text { Linhas de } \\
\text { pesquisa }\end{array}$ & Ementa \\
\hline $\begin{array}{l}\text { Em comunica- } \\
\text { ção e informa- } \\
\text { ção da UFR- } \\
\text { GS (mestrado e } \\
\text { doutorado) }\end{array}$ & $\begin{array}{l}\text { Informação, tec- } \\
\text { nologias e práti- } \\
\text { cas sociais }\end{array}$ & $\begin{array}{l}\text { Pesquisas de cunho teórico, metodológico e aplicado, enfocando geração, desenvolvimento e } 0 \\
\text { uso da informação e tecnologias da informação e da comunicação, para compreensão da ci-- } \\
\text { bercultura, da interação mediada por computador e demais fenômenos da dinâmica das prá- } \\
\text { ticas sociais. }\end{array}$ \\
\hline $\begin{array}{l}\text { Em comunicação } \\
\text { da UFF (Mestra- } \\
\text { do e Doutorado) }\end{array}$ & $\begin{array}{l}\text { Tecnologias da } \\
\text { comunicação e } \\
\text { da informação }\end{array}$ & $\begin{array}{l}\text { Análise das tecnologias da comunicação e da informação, tendo em vista o seu impacto social, eco- } \\
\text { nômico e político e suas formas de apropriação cultural. }\end{array}$ \\
\hline $\begin{array}{l}\text { Em comunica- } \\
\text { ção da UNESP } \\
\text { (Mestrado) }\end{array}$ & $\begin{array}{l}\text { Gestão da in- } \\
\text { formação e co- } \\
\text { municação mi- } \\
\text { diática }\end{array}$ & $\begin{array}{l}\text { Investiga o fluxo da comunicação e da informação, abordando a geração, veiculação e gestão do co- } \\
\text { nhecimento midiático, os processos de inovação tecnológica na produção e transmissão de mensa- } \\
\text { gens e os meios tradicionais e tecnologias emergentes. }\end{array}$ \\
\hline $\begin{array}{l}\text { Da escola de co- } \\
\text { municação da } \\
\text { UFRJ }\end{array}$ & $\begin{array}{l}\text { Mídia e media- } \\
\text { ções sociocul- } \\
\text { turais }\end{array}$ & $\begin{array}{l}\text { Desenvolvimento de metodologias e análises críticas dos fenômenos comunicativos, presentes tan- } \\
\text { to nas produções da mídia, quanto nas instituições de mediação tradicional e nas práticas sociocul- } \\
\text { turais. Investiga ainda as dinâmicas sociais e os múltiplos recursos advindos da gestão da informa- } \\
\text { ção e do conhecimento, no âmbito dos dispositivos mediáticos. }\end{array}$ \\
\hline $\begin{array}{l}\text { Em comunica- } \\
\text { ção da UnB }\end{array}$ & $\begin{array}{l}\text { Teorias e tecno- } \\
\text { logias da comu- } \\
\text { nicação }\end{array}$ & $\begin{array}{l}\text { Acompanhar criticamente os problemas que emergem com a Sociedade da Informação, a partir da } \\
\text { introdução da tecnologia nos processos de comunicação social e integração dos meios de comuni- } \\
\text { cação à organização das sociedades complexas. Análise crítica do conhecimento gerado pelos meios } \\
\text { de comunicação, sejam os aspectos teórico-epistemológicos dos saberes, sejam os aspectos mais } \\
\text { pontuais, como a convergência mediática, a globalização, as campanhas publicitárias e o espaço } \\
\text { público gerados pelos mass medias e demais temáticas que configuram o universo da mediação } \\
\text { tecnológica. Neste sentido, busca extrair as implicações do uso das tecnologias de comunicação na } \\
\text { organização social contemporânea. }\end{array}$ \\
\hline $\begin{array}{l}\text { Em comunica- } \\
\text { ção social da } \\
\text { PUCRS }\end{array}$ & $\begin{array}{l}\text { Cultura midiáti- } \\
\text { ca e tecnologias } \\
\text { do imaginário }\end{array}$ & $\begin{array}{l}\text { Reflexão e investigação dos processos de comunicação e de suas transformações, diante das } \\
\text { mudanças que as novas tecnologias de informação e de representação introduzem nas culturas } \\
\text { e nas sociedades contemporâneas por meio dos imaginários dos sujeitos. Tecnologia como ele- } \\
\text { mento de mediação entre cultura e imaginário, entendido como apropriação (recorte) individual } \\
\text { ou grupal da cultura sob, neste caso, a influência de tecnologias de contato. Cultura midiática e } \\
\text { tecnologias do imaginário como elementos especulares, uns refletindo e dependendo dos outros. } \\
\text { Propondo-se a: refletir sobre os significados filosófico e sociológico das transformações cultu- } \\
\text { rais nos vários planos da vida coletiva com o progresso das tecnologias de comunicação. A par- } \\
\text { tir de perspectivas teóricas consolidadas e emergentes, visa promover reflexão e pesquisa das } \\
\text { relações instituídas e por serem estabelecidas entre o homem e a técnica; desenvolver reflexões } \\
\text { sobre a produção e significação das mensagens que materializam os desejos do imaginário dos } \\
\text { sujeitos contemporâneos, nos planos visual e verbal, pela análise das características mais signi- } \\
\text { ficantes das representações materiais que englobem tanto efeitos estéticos quanto persuasivos } \\
\text { ou informacionais. Representações visuais e verbais das tecnologias analógicas tradicionais ou } \\
\text { novas tecnologias eletrônico-digitais. }\end{array}$ \\
\hline $\begin{array}{l}\text { Em comunica- } \\
\text { ção e cultura } \\
\text { contemporânea } \\
\text { da UFBA }\end{array}$ & Cibercultura & $\begin{array}{l}\text { Análise das formas mediáticas surgidas da convergência da informática e das telecomunicações. } \\
\text { Visa compreender os novos meios digitais emergentes no que se refere às diversas formações so- } \\
\text { cioculturais online, às novas práticas e formatos jornalísticos e } 0 \text { atual fenômeno técnico-medi- } \\
\text { ático em sua interface com a atividade política. } 0 \text { campo da cibercultura agrega estudos sobre } \\
\text { os impactos comunicacionais das tecnologias de informação e comunicação no mundo contem- } \\
\text { porâneo. }\end{array}$ \\
\hline
\end{tabular}


Quadro 4: Interfaces da informação e comunicação nas ementas das linhas de pesquisa dos PPGCIs.

\begin{tabular}{|c|c|c|}
\hline $\begin{array}{l}\text { Programas de } \\
\text { pós-graduação }\end{array}$ & $\begin{array}{l}\text { Linhas de } \\
\text { Pesquisa }\end{array}$ & Ementa \\
\hline $\begin{array}{l}\text { Em ciência da } \\
\text { informação da } \\
\text { UFBA }\end{array}$ & $\begin{array}{l}\text { Informação e co- } \\
\text { nhecimento em } \\
\text { ambientes orga- } \\
\text { nizacionais }\end{array}$ & $\begin{array}{l}\text { Compreende estudos: da relação informaçãa e conhecimento; informação e tecnologias de informa- } \\
\text { ção e comunicação; informação e processo cognitivo; da inteligência organizacional, abrangendo ges- } \\
\text { tão da informação e gestão do conhecimento. Inclui a compreensão: do desenvolvimento do conheci- } \\
\text { mento na Sociedade; e da definição da Ciência da Informação e sua relação com a epistemologia. }\end{array}$ \\
\hline $\begin{array}{l}\text { Em ciência da } \\
\text { in form a çã } 0 \\
\text { UNESP MARILIA }\end{array}$ & $\begin{array}{l}\text { Informação e } \\
\text { tecnologia }\end{array}$ & $\begin{array}{l}\text { Abrange estudos e pesquisas relacionados à geração, transferência, utilização e preservação da in- } \\
\text { formação e de documentos nos ambientes científicos, tecnológicos, empresariais e da sociedade em } \\
\text { geral, associados a métodos e instrumentos proporcionados pelas tecnologias da informação e co- } \\
\text { municação. A linha tem por objetivo a análise dos impactos que as tecnologias da informação e da } \\
\text { comunicação têm causado nos processos informacionais em distintas ambiências. }\end{array}$ \\
\hline $\begin{array}{l}\text { Em ciência da } \\
\text { informação da } \\
\text { UnB }\end{array}$ & $\begin{array}{l}\text { Comunicação } \\
\text { científica }\end{array}$ & $\begin{array}{l}\text { Modelos e processos da comunicação da informação científica, tecnológica, comunitária, arquivís- } \\
\text { tica, organizacional e para negócios. Suportes informacionais tradicionais e eletrônicos. Direito au- } \\
\text { toral. Influência dos contextos acadêmico, industrial, empresarial. }\end{array}$ \\
\hline $\begin{array}{l}\text { Em ciência da } \\
\text { informação da } \\
\text { UFMG }\end{array}$ & $\begin{array}{l}\text { Organização e } \\
\text { uso da infor- } \\
\text { mação }\end{array}$ & $\begin{array}{l}\text { A linha de pesquisa inclui estudos sobre descrição física e temática de documentos, bem como es- } \\
\text { tudos bibliométricos. Tem como subtemas: Tratamento bibliométrico da informação; Softwares apli- } \\
\text { cados ao tratamento da informação; Linguagens de indexação; Análise de assunto; Bases de dados } \\
\text { documentais; Automação de bibliotecas; Bibliotecas universitárias; Bibliotecas especializadas; Re- } \\
\text { des de intercâmbio de dados bibliográficos; Indexação da Internet; Metadados; Tratamento integra- } \\
\text { do de informações nas empresas; Sistemas e serviços de informação; Elaboração de índices; Teoria } \\
\text { do conceito; Classificação do conhecimento; Organização do conhecimento; Comunicação Cientí- } \\
\text { fica; Estudos dos padrões de produção do conhecimento nas diversas disciplinas; Análise de cita- } \\
\text { ções; Tratamento e recuperação da informação jurídica. }\end{array}$ \\
\hline $\begin{array}{l}\text { Em ciência da } \\
\text { informação da } \\
\text { UFF/IBICT }\end{array}$ & $\begin{array}{l}\text { Representação, } \\
\text { gestão e tecno- } \\
\text { logia da infor- } \\
\text { mação }\end{array}$ & $\begin{array}{l}\text { Estudo das diferentes formas de mediação dos processos cognitivos, comunicacionais e sociais, } \\
\text { considerando a informação como objeto de uma ação de intervenção. Investigação dos fluxos, pro- } \\
\text { cessamento e gestão da informação em contextos distintos. Estudos de necessidades e usos da in- } \\
\text { formação em seus diferentes contextos. Ênfase na organização de domínios de conhecimento, na re- } \\
\text { presentação da informação e nas tecnologias de informação e comunicação. }\end{array}$ \\
\hline
\end{tabular}

Quadro 5: Interdisciplinaridade nas ementas das linhas de pesquisa dos PPGCIs e dos PPGCOMs.

\begin{tabular}{|c|c|c|}
\hline $\begin{array}{l}\text { Programas de } \\
\text { pós-graduação }\end{array}$ & $\begin{array}{l}\text { Linhas de } \\
\text { Pesquisa }\end{array}$ & Ementa \\
\hline $\begin{array}{l}\text { Em ciências da } \\
\text { comunicação da } \\
\text { USP (mestrado e } \\
\text { doutorado) }\end{array}$ & $\begin{array}{l}\text { Epistemologia, } \\
\text { teorias e meto- } \\
\text { dologias da co- } \\
\text { municação }\end{array}$ & $\begin{array}{l}\text { A perspectiva comunicacional procura elaborar o conhecimento nos terrenos de interconexão das } \\
\text { disciplinas atuando contra o princípio da fragmentação positivista. A interdisciplinaridade que mar- } \\
\text { ca essa perspectiva busca abarcar a multiplicidade de níveis e aspectos, próprios do princípio da } \\
\text { causalidade complexa que rege o objeto comunicacional. Essa linha tem como foco as tendências } \\
\text { atuais de crítica e renovação das teorias e metodologias de pesquisa em comunicação, traduzindo- } \\
\text { as na construção de objetos teóricos de investigação e em instrumentais metodológicos para proje- } \\
\text { tos a serem desenvolvidos pelos alunos do curso. }\end{array}$ \\
\hline $\begin{array}{l}\text { Área de concen- } \\
\text { tração: comuni- } \\
\text { cação }\end{array}$ & $\begin{array}{l}\text { Comunicação e } \\
\text { educação }\end{array}$ & $\begin{array}{l}\text { As disciplinas incluídas nesta linha, a partir de uma ótica interdisciplinar, desenvolvem trabalhos } \\
\text { em duas áreas: Educação para Comunicação, englobando pesquisas para a leitura crítica da Comu- } \\
\text { nicação; Pedagogia da Comunicação, englobando pesquisas no campo do uso dos recursos da Co- } \\
\text { municação como mediação privilegiada do processo ensino-aprendizagem. }\end{array}$ \\
\hline $\begin{array}{l}\text { Em ciência da } \\
\text { informação da } \\
\text { UNESP-MARILIA }\end{array}$ & $\begin{array}{l}\text { Organização da } \\
\text { informação }\end{array}$ & $\begin{array}{l}\text { Considera a organização da informação como elemento para garantia de qualidade na recuperação. } \\
\text { Destaca-se o desenvolvimento de referenciais teóricos e metodológicos interdisciplinares que pro- } \\
\text { piciem a elaboração de produtos documentários temáticos como reflexo de procedimentos de análi- } \\
\text { se (com especial ênfase na leitura documentária e no método diplomático), síntese, condensação e } \\
\text { representação do conteúdo informacional. Ressaltam-se, como dimensão teórica, a organização do } \\
\text { conhecimento e, como dimensão aplicada, a formação e atuação profissional, bem como a produ- } \\
\text { ção científica na área. A ótica da linha encontra-se centrada basicamente no processo de organiza- } \\
\text { ção temática da informação, em suas dimensões de análise, síntese e representação, a partir dos } \\
\text { processos, produtos e instrumentos a elas peculiares. Neste contexto, tem-se como decorrência o } \\
\text { processo de recuperação temática da informação. }\end{array}$ \\
\hline $\begin{array}{l}\text { Em ciência da } \\
\text { informação da } \\
\text { UFF/IBICT }\end{array}$ & $\begin{array}{l}\text { Teoria, episte- } \\
\text { mologia, inter- } \\
\text { disciplinaridade } \\
\text { e ciência da in- } \\
\text { formação }\end{array}$ & $\begin{array}{l}\text { Estudos orientados à reconstrução crítica das estratégias e premissas epistemológicas constituídas } \\
\text { no campo da Ciência da Informação e sua interdisciplinaridade, assim como ao desenvolvimento de } \\
\text { conceitos, metodologias, modelos e teorias dos fenômenos, processos e construtos de informação. }\end{array}$ \\
\hline
\end{tabular}


to do espaço comunicacional denominado cibercultura. Em outras linhas, como "Tecnologias da Comunicação e Informação", da UFF, "Teorias e Tecnologias da Comunicação", da UnB, "Cultura Midiática e Tecnologias do Imaginário", da PUCRS, e "Cibercultura”, da UFBA, transparece a preocupação com a pesquisa sobre os impactos das tecnologias na sociedade e suas formas de apropriação políticas, econômicas e culturais. A linha da UnB cita o acompanhamento dos problemas que emergem com a Sociedade da Informação como eixo de estudos. Em todas, o termo "informação" está ligado à comunicação por meio das tecnologias, com enfoque para as novas formas de sociabilidade geradas pelos avanços tecnológicos. Já as linhas "Mídia e Mediações Socioculturais", da UFRJ, e "Gestão da Informação e Comunicação Midiática", da UNESP, preocupam-se com o fluxo da comunicação e da informação, abordando geração, veiculação e gestão da informação e do conhecimento no âmbito dos dispositivos midiáticos. Assim, liga-se a informação à comunicação através da gestão do conhecimento e seus processos de divulgação na mídia.

$\mathrm{Na}$ análise da categoria "Informação e Comunicação", o termo "comunicação" é tratado nas ementas das linhas de pesquisa dos PPGCIs no âmbito das TICs, da divulgação da ciência e da representação e mediação das práticas sociais. As linhas "Informação e Conhecimento em Ambientes Organizacionais", da UFBA, "Informação e Tecnologia", da UNESP, e "Representação, Gestão e Tecnologia da Informação", da UFF/IBICT, apresentam a interface da comunicação com a informação por meio das TICs, analisando seus impactos nos processos informacionais em distintas ambiências. Os enfoques ao estudo das tecnologias manifestam tendência tecnicista para investigação sobre mé- todos, instrumentos e produtos gerados pelas TICs nos ambientes científicos e sociais. Cabe ressaltar que a linha da UFF/IBICT, ao considerar a informação como um objeto de ação intervencionista, se preocupa com suas mediações nos processos cognitivos, comunicacionais e sociais, numa abordagem interfaciada com outros campos e diversa das dos outros programas. Ainda, ao tratar da representação da informação, evidencia relações com a Semiótica. As linhas que tratam da comunicação científica são: "Organização e Uso da Informação", da UFMG, e "Comunicação Científica”, da UnB. Nessa abordagem, a comunicação liga-se à informação mediante a divulgação da ciência por canais específicos, como, por exemplo, o estudo dos periódicos científicos, que é um dos objetos de pesquisa recorrentes nos PPGCIs.

Em relação à categoria "Interdisciplinaridade", as interfaces entre a Comunicação e a Ciência da Informação permeiam algumas linhas. Como exemplo, a linha "Epistemologia, Teorias e Metodologias da Comunicação", da USP, aborda a interdisciplinaridade para estudar o campo de interface das disciplinas com o objeto comunicacional. Nas linhas "Organização da Informação", da UNESP, e "Teoria, Epistemologia, Interdisciplinaridade e Ciência da Informação", da UFF/IBICT, as pesquisas voltamse para o estudo do campo da informação e suas inter-relações com outras áreas do conhecimento, com o objetivo de desenvolver o aporte teórico. A linha da UNESP centra-se no processo de organização da informação, tendo em vista sua representação e recuperação.

Percebe-se que, na interface entre comunicação e informação, as TICs, bem como a organização, representação e gestão da informação, são convergências entre os campos, no senti- 
do de se constituírem como objeto de estudo em comum, porém com abordagens distintas. Enquanto a Comunicação tende a visualizar os impactos sociais das TICs, a Ciência da Informação tem se preocupado, principalmente, com sua aplicação nos processos e sistemas de armazenagem e recuperação de informaçóes. Tanto uma quanto a outra área estão ampliando suas fronteiras: a Ciência da Informação volta-se para as questôes sociais, enquanto que a Comunicação se dirige, cada vez mais, para o uso dos recursos e técnicas informacionais.

A gestão do conhecimento é outro ponto de interface, onde a Comunicação sente a necessidade de gerenciar $\mathrm{o}$ fluxo desordenado de informaçôes que transitam, atualmente, nos mais variados formatos e suportes. Nesse sentido, pode-se citar Azevedo Netto (1999), que considera os processos informacionais no interior da comunicação, dirigindo-se à interação de indivíduos na sociedade, e Hohlfeldt (2001), que caracteriza a Comunicação como fenômeno social, trazendo, em essência, a necessidade do ser humano de trocar e compartilhar informações e sentidos por meio da representação existente na linguagem, configurando-se, então, alguns espaços de interfaces entre os campos.

\section{Considerações finais}

O estudo das ementas das linhas de pesquisa dos programas de PósGraduação em Comunicação e em Ciência da Informação revelou algumas interfaces já configuradas entre as áreas e, principalmente, possibilidades de desenvolvimento de pesquisas que contemplem os dois campos. As definições e características das ciências da Comunicação e da Informação demonstraram que as interfaces de fato existem e, se estudadas conjunta- mente, podem progredir, contribuindo para o avanço do conhecimento nas áreas.

Contudo, notou-se que a maior parte da pesquisa tem acontecido isoladamente, pois os objetos permeiam e são permeados por questôes que abrangem, na maioria, interesses específicos de cada área. Há uma tendência de preservação do próprio campo, percebida quando se evitam termos que tornariam mais evidentes as relações. Um exemplo é o uso da expressão "tecnologias da comunicação" pela Comunicação como sinônimo de "tecnologias da informação e da comunicação", que representam uma convergência.

Há muitas possibilidades de interação entre os campos; tal interação somente será possível quando a pesquisa se apropriar do espaço de interfaces, produzindo conhecimentos que levem à constituição de objetos comuns. São ambas as disciplinas transversais por natureza, pois não existe área que, de alguma forma, não se aproprie da informação e da comunicação para se afirmarem como campo científico.

Este estudo utilizou como objeto as ementas das linhas de pesquisa e, dessa forma, não pode ser considerado exaustivo, uma vez que não permite visualizar totalmente os aspectos pertinentes à pesquisa realizada nos programas de pós-graduação. Sugerem-se outras investigaçóes, como análise das interfaces em teses e dissertações, mas consideram-se cumpridos os objetivos do trabalho. Entretanto, como as interfaces ainda não estão totalmente consolidadas, muitas questões precisam ser delineadas, traçando-se limites, mas, ao mesmo tempo, abrindo fronteiras interdisciplinares que devem ser exploradas e debatidas continuamente, sem reservas e barreiras, que apenas dificultam o surgimento de novos paradigmas nas ciências. 


\section{Abstract}

This paper is a result of studies about the relationships between Communication and Information Science, developed by the Scientific Communication Group from PPGCOM/UFRGS. It involved testing a methodology to identify interfaces between Communication and Information Science, through the analysis of research lines descriptions of Communication and Information Postgraduate Programs in Brazil. The results showed that technology, organization, representation and information management are convergence areas in the two fields, although presenting different approaches. Both sciences are enlarging their interdisciplinary borders: Information Science is directing itself to social subjects and Communication to the use of information resources and techniques, thus delineating fresh approaches for the appearance of new paradigms.

Key-words: information science, communication, postgraduate studies, interfaces.

\section{Referências}

AZEVEDO NETTO, C. X. de. Uma face da Ciência da Informação. In: PINHEIRO, L. V. R. (Org.). Ciência da Informação, Ciências Sociais e interdisciplinaridade. Brasília, DF: IBICT, 1999. p. 133-142.

BARRETO, A. A questão da informação. São Paulo em Perspectiva, São Paulo, v. 8, n. 4, p. 3-8. 1994.

BRAGA, J. L. Os estudos de interface como espaço de construção do campo da Comunicação. In: ASSOCIAÇÃO NACIONAL DOS PROGRAMAS DE PÓS-GRADUAÇÃO EM COMUNICAÇÃO - COMPÓS. 13., São Bernardo do Campo, 2004. Anais... São Paulo, 2004 .

CAPURRO, R. Epistemologia e Ciência da Informação. In: ENCONTRO NACIONAL DE PESQUISA EM CIÊNCIA DA INFORMAÇÃO, 5., Belo Horizonte, 2003. Anais eletrônicos... Belo Horizonte: ANCIB, 2003. 1 CDROM.
CARVAlHO, E. C. A natureza social da Ciência da Informação. In: PINHEIRO, L. V. R. (Org.). Ciência da Informação, Ciências Sociais e interdisciplinaridade. Brasília, DF: IBICT, 1999. p. 51-64.

COORDENAÇÃO DE APERFEIÇOAMENTO DE PESSOAL DE NÍVEL SUPERIOR - CAPES. Disponível em: <http://wwwl.capes.gov.br>. Acesso em: 05 jul. 2006.

DEVÉZE, J. As ciências da Informação e da Comunicação na França: no caminho de uma hermenêutica da troca humana e social. In: LOPES, M. I.; FRAUMEIGS, D.; SANTOS, M. S. T. (Org.). Comunicação e Informação: identidades e fronteiras. São Paulo: Bagaço, 2000.

FAUSTO NETO, A. Condiçõoes da pesquisa em Comunicação no Brasil. Revista Famecos, Porto Alegre, n. 5, p. 82-90, dez. 1996.

FRANÇA, V. V. O objeto da Comunicação/A Comunicação como objeto. In: HOHLFELDT, A.; MARTINO, L. C.; FRANÇA, V. V. Teorias da Comunicação: conceitos, escolas e tendências. Petrópolis, RJ: Vozes, 2001. p. 39-60.

HOHLFELDT, A. As origens antigas: a Comunicação e as civilizações. In: HOHLFELDT, A.; MARTINO, L. C.; FRANÇA, V. V. Teorias da Comunicação: conceitos, escolas e tendências. Petrópolis, RJ: Vozes, 2001. p. 61-98.

ISSLER, B. Objetos de pesquisa e campo comunicacional. In: WEBER, M. H.; BENTZ, I.; HOHLFELDT, A. Tensões e objetos: da pesquisa em comunicação. Porto Alegre: Sulina, 2002. p. 36-51.

JACKS, N.a. Altos estudos em Comunicação: a experiência da pós-graduação brasileira. In: SEMINÁRIO INTERNACIONAL SOBRE PÓS-GRADUAÇÃO NA AMÉRICA LATINA. México, 2003. Anais... México: Universidade de Vera Cruz, 2003.

LE COADIC, Yves-François. Ciência da Informação. Brasília: Briquet de Lemos, 1996. 
LOUREIRO, J. M. M. Ciência da Informação: nem ciência social, nem humana, apenas uma ciência diferente. In: PINHEIRO, L. V. R. (Org.). Ciência da Informação, Ciências Sociais e interdisciplinaridade. Brasília, DF: IBICT, 1999. p. 65-78.

MARTINO, L. C. De qual Comunicação estamos falando? In: HOHLFELDT, A.; MARTINO, L. C.; FRANÇA, V. V. Teorias da Comunicação: conceitos, escolas e tendências. Petrópolis, RJ: Vozes, 2001. p. 11-26.

MERTA, A. Informatics as a branch of science. In: INTERNATIONAL FEDERATION FOR DOCUMENTATION. Study Committee Research on Theoretical Basis of Information. Moscow: All-Union for Scientific and Technical Information, 1969. p. 7-24.

MORAES, R. Análise de Conteúdo. Educação, Porto Alegre, ano XXII, n. 37, p. 7-32, 1999.

OLIVEIRA, M. de. A investigação cientifica na ciência da informação: análise da pesquisa financiada pelo CNPq. 1998. Tese (Doutorado em Biblioteconomia) Programa de Pós-Graduação em Ciência da Informação, Universidade de Brasília, Brasília, 1998.

MUELLER, S. P. M. Reflexões sobre a formação profissional para biblioteconomia e sua relação com as demais profissões da informação. Transinformação, Campinas, v. 1, n. 2, p. 175-178, maio/ago. 1989.

OROZCO GÓMEZ, G. La investigacion en comunicacion desde la perspectiva cualitativa. La Plata: Epc, 1996.

PERUZZO, C. M. K. Em busca dos objetos de pesquisa em Comunicação no Brasil. In: WEBER, M.; BENTZ, I.; HOHLFELDT, A. Tensóes e objetos: da pesquisa em Comunicação. Porto Alegre: Sulina, 2002. p. 52-72.

PINHEIRO, L. V. R. Campo interdisciplinar da Ciência da Informação: fronteiras remotas e recentes. In: __. (Org.). Ciência da Informação, Ciências Sociais e interdisciplinaridade. Brasília, DF: IBICT, 1999. p. 155-182.

PINHEIRO, L. V. R. Informação: esse obscuro objeto da Ciência da Informação. Morpheus, Rio de Janeiro, Ano 2, n. 4, 2004. Disponível em: <http://www.unirio.br/cead/morpheus/Numero04-2004/ Ipinheiro.htm>. Acesso em: 10 out. 2005.

SANTAELLA, L. Porque a semiótica de Peirce é também uma teoria da comunicação. Revista de Comunicação e Linguagens: o campo da Semiótica, Lisboa, n. 29, maio 2001.

SARACEVIC, T. Interdisciplinary $\mathrm{Na}$ ture of Information Science. Ciência da Informação, Brasília, v. 24, n. 1, p. 36-41, jan./abr. 1995.

SARACEVIC, T. Information Science. Journal of the American Society for Information Science, Maryland, v. 50, n. 12, p. 1051-1-63, 1999.

SHANNON, C.; WEAVER, W. The mathematical theory of communication urban. Illinois: University of Illinois, 1949. 